\title{
PENETAPAN KRITERIA PENILAIAN KERUSAKAN BETON PADA BANGUNAN GEDUNG BERDASARKAN SKALA PRIORITAS
}

\author{
Henny Wiyanto ${ }^{1}$, Edric Justin ${ }^{2}$ \\ ${ }^{1}$ Jurusan Teknik Sipil, Fakultas Teknik, Universitas Tarumanagara Jakarta \\ Email: hennyw@ft.untar.ac.id \\ ${ }^{2}$ Program Studi Sarjana Teknik Sipil, Jurusan Teknik Sipil, Fakultas Teknik, Universitas Tarumanagara Jakarta \\ Email:edricjustin@yahoo.com
}

Masuk: 30-08-2019, revisi: 03-09-2019, diterima untuk diterbitkan: 02-10-2019

\begin{abstract}
ABSTRAK
Pembangunan bangunan gedung wajib dilaksanakan secara tertib administratif dan teknis untuk menjamin keandalan bangunan gedung tanpa menimbulkan dampak penting terhadap lingkungan. Keandalan bangunan gedung adalah kondisi keselamatan, kesehatan, kenyamanan, dan kemudahan yang memenuhi persyaratan teknis oleh kinerja bangunan gedung. Tingkat keandalan suatu bangunan dapat diketahui dengan melakukan penilaian terhadap kondisi struktur bangunan. Seiring berjalannya waktu, struktur bangunan dapat mengalami kerusakan dan menimbulkan risiko besar bagi pengguna bangunan. Untuk mengurangi risiko akibat kerusakan struktur maka perlu diketahui aspek-aspek yang dapat menyebabkan terjadinya kerusakan. Penilaian tingkat keandalan struktur beton dilakukan dengan menetapkan kriteria penilaian kerusakan beton pada bangunan gedung berdasarkan skala prioritas. Penilaian skala prioritas kriteria kerusakan pada struktur beton ditetapkan berdasarkan pendapat para ahli, sehingga penilaian bersifat deskriptif. Untuk mengantisipasi permasalahan tersebut maka penetapan skala prioritas dilakukan dengan pendekatan Fuzzy Logic untuk mewakili adanya ketidakpastian yang digabungkan dengan metode Analytic Hierarchy Process (AHP) sebagai alat pengambilan keputusan. Dalam Hasil penelitian menunjukan kriteria, sub kriteria 1, dan sub kriteria 2 dengan skala prioritas tertinggi. Secara keseluruhan kriteria penilaian kerusakan beton dengan skala prioritas tertinggi adalah paparan dan korosi pada tulangan, penurunan tanah, dan dinding geser. Dapat diartikan pula bahwa kriteria dengan skala prioritas tertinggi merupakan aspek yang harus diperhatikan dalam perencanaan, pelaksanaan, dan pemeliharaan bangunan.
\end{abstract}

Kata Kunci: Kriteria kerusakan beton; Bangunan gedung; Skala prioritas

\begin{abstract}
Building construction must be executed in an orderly, administrative, and technical way to ensure the building's reliability without causing any significant drawback to the environment. Building reliability is safety conditions, health, comfort, and ease that fulfill the technical terms from building performance. A building's reliability rating can be identified by assessing the building structure condition. As time goes, building structure can experience damage and cause high risk for the building's users. To reduce risk from structure damage, the aspects that can cause damage need to be identified. Concrete structure reliability rating assessment is done by determining concrete damage assessment criteria on building based on priority scale. Priority scale assessment on concrete structure is determined based on expert opinion, so the assessment is descriptive. To anticipate that problem, priority scale determination is done by using the Fuzzy Logic approach to represent uncertainty, which is combined with the Analytic Hierarchy Process (AHP) method as a decision making tool. In the research results are shown the criteria, sub criteria 1, and sub criteria 2 with high priority scale. As a wholethe concrete damage assessment criteria with the highest priority scale is exposure and corrosion on the reinforcement, land subsidence, and sliding wall. It can also be interpreted that the criteria with the highest priority scale are the aspects that have to be watched out for in building planning, implementation, and maintenance.
\end{abstract}

Keywords: Concrete damage criteri; building; priority scale 


\section{PENDAHULUAN}

Beton merupakan material pembentuk struktur bangunan yang mepunyai sifat sangat kuat terhadap beban tekan tetapi lemah terhadap beban tarik. Dalam konstruksi bangunan, material beton selalu digabung dengan tulangan untuk melengkapi kekuatan struktur bangunan. Selama proses pemanfaatan bangunan, beton dapat mengalami kerusakan yang disebabkan oleh faktor alam atau faktor manusia. Penyebab kerusakan yang tergolong faktor tidak dapat dicegah oleh manusia, tetapi yang tergolong faktor manusia seharusnya dapat diantisipasi dalam perencanaan proyek. Untuk dapat mengurangi risiko akibat kerusakan struktur beton maka perlu diketahui faktor-faktor yang dapat menyebabkan terjadinya kerusakan. Kerusakan beton merupakan perubahan kondisi fisik beton pada suatu bangunan.

Untuk mengantisipasi terjadinya kerusakan maka dalam pemanfaatan bangunan gedung, pemilik atau pengguna wajib melakukan tertib administratif dan teknis untuk menjamin kelaikan fungsi bangunan gedung tanpa menimbulkan dampak penting terhadap lingkungan, termasuk kegiatan pemeliharaan, perawatan, pemeriksaan berkala, pelestarian, dan pembongkaran. Persyaratan teknis bangunan gedung meliputi persyaratan tata bangunan dan persyaratan keandalan bangunan gedung (UU RI No.28 Tahun 2002, pasal 7). Persyaratan keandalan bangunan gedung meliputi persyaratan keselamatan, kesehatan, kenyamanan, dan kemudahan yang ditetapkan berdasarkan fungsi bangunan gedung. Salah satu persyaratan keselamatan bangunan gedung adalah kemampuan bangunan gedung untuk mendukung beban muatannya. Keandalan suatu bangunan dapat diketahui melalui penilaian terhadap tingkat kondisi strukturnya.

Penilaian kondisi suatu bangunan dapat dilakukan untuk sejumlah tujuan seperti pengembangan kinerja bangunan, penetapan penggunaan atau fungsi bangunan, kemudahan servis bangunan, perencanaan pemeliharaan atau perbaikan bangunan, keselamatan jiwa pengguna bangunan, daya tahan, pelestarian sejarah, serta sejumlah tujuan khusus berdasarkan spesifik bangunan itu sendiri (ASCE 30-14). Penilaian kondisi struktur bangunan gedung merupakan hal penting tetapi banyak diabaikan karena cenderung memerlukan biaya besar. Penilaian kerusakan pada beberapa kasus tidak dapat dilakukan dengan sederhana, karena memerlukan tenaga ahli khusus dan data yang terbatas. Hal ini menunjukan bahwa ketika mengasumsikan makna dan perilaku terjadi ketidakpastian, ambiguitas, dan ketidaktepatan (Hamdia, et. al., 2018).

Berdasarkan uraian diatas perlu diidentifikasi kriteria dalam melakukan penilaian kondisi struktur bangunan, serta metode yang cocok digunakan dalam menetapkan kriteria penilaian tersebut.

\section{METODE PENELITIAN}

Penelitian ini dilakukan untuk menetapkan kriteria penilaian kerusakan beton pada bangunan gedung berdasarkan skala prioritas. Penelitian di awali dengan mengidentifikasi Kriteria-kriteria penilaian kerusakan struktur beton pada bangunan gedung melalui studi literatur (Kim, et. al., 2006, Hamdia, et. al., 2018, dan Portland Cement Association, 2002). Kriteria penilaian yang diidentifikasi merupakan kriteria yang dapat diperiksa secara visual yang sesuai dengan kondisi di Indonesia. Pemeriksaan visual merupakan pemeriksaan pada permukaan struktur beton yang dapat diakses dengan indera penglihatan.

Kriteria penilaian yang telah teridentifikasi diolah dan dianalisis untuk memperoleh skala prioritas. Penetapan skala prioritas dilakukan dengan pendekatan Fuzzy Logic (Zadeh, 1999) untuk mewakili adanya ketidakpastian yang digabungkan dengan metode Analytic Hierarchy 
Process (AHP) sebagai alat pengambilan keputusan multi kriteria (Saaty, 2001). Hasil penelitian menunjukan kriteria penilaian kerusakan beton dengan prioritas tertinggi, dengan langkah sebagai berikut:

a. Menyusun matriks perbandingan berpasangan berdasarkan kriteria utama, sub kriteria, dan sub sub kriteria dengan formula sebagai berikut:

$\begin{array}{ccccc}\text { C } & \text { A1 } & \text { A2 } & \ldots & \mathrm{A}_{\mathrm{n}} \\ \mathrm{A} 1 & 1 & \alpha_{12} & \ldots & \alpha_{1 \mathrm{n}} \\ \mathrm{A} 2 & \alpha_{21} & 1 & \ldots & \alpha_{2 \mathrm{n}} \\ \ldots & \ldots & \ldots & \ldots & \ldots \\ \mathrm{A}_{\mathrm{n}} & \alpha_{\mathrm{n} 1} & \alpha_{\mathrm{n} 2} & \ldots & 1\end{array}$

Nilai $\alpha_{\mathrm{ij}}$ adalah nilai perbandingan elemen $\alpha_{\mathrm{i}}$ terhadap elemen $\alpha_{\mathrm{j}}$, yang menyatakan hubungan seberapa besar tingkat kepentingan elemen $\alpha_{\mathrm{i}}$ bila dibandingkan dengan elemen $\alpha_{\mathrm{j}}$ terhadap kriteria $\mathrm{C}$.

Perbandingan antara kriteria penilaian kerusakan beton ditetapkan berdasarkan pendapat para ahli bidang konstruksi beton melalui kuesioner.

b. Menentukan vektor prioritas setiap kriteria dalam hierarki.

c. Melakukan uji konsistensi pada setiap matriks perbandingan berpasangan. Jika CR $\leq 10 \%$, maka matriks perbandingan berpasangan tersebut dianggap konsisten. Untuk setiap matriks perbandingan berpasangan yang tidak konsisten perlu dilakukan perbaikan dengan langkah:

- Menentukan bobot prioritas

$$
\text { Bobot prioritas }=\left[\frac{\text { vektor bobot }}{\text { vektor prioritas }}\right]
$$

- Menentukan $\lambda_{\max }$ (nilai eigen terbesar) dengan merata-ratakan bobot prioritas

$$
\lambda_{\max }=\frac{\text { jumlah bobot prioritas }}{\text { ordo matriks }}
$$

- Menentukan indeks konsistensi (CI)

$$
\mathrm{CI}=\frac{\lambda \text { max }- \text { ordo matriks }}{\text { ordo matriks }-1}
$$

- Menentukan konsistensi rasio (CR)

$$
\mathrm{CR}=\frac{C I}{R I}
$$

d. Mentransformasikan bobot pada matriks perbandingan berpasangan ke dalam bilangan triangular fuzzy.

Penilaian dilakukan dengan mengacu pada bilangan tingkat intensitas kepentingan dari metode AHP dan ditransformasikan ke dalam himpunan skala Triangular Fuzzy Number (TFN). Representasi Segitiga (Triangular) mempunyai tiga buah parameter, yaitu $a, b, c$ dengan $a<b<c$, yang dinyatakan dengan segitiga $(x ; a, b, c)$. Fungsi keanggotaan dari TFN adalah sebagai berikut:

$$
\text { Fungsi Keanggotaan TFN: } \mu(x)=\left\{\begin{array}{l}
0 ; x \leq a \text { atau } x \geq c \\
\frac{(x-a)}{(b-a)} ; a \leq x \leq b \\
\frac{(b-x)}{(a-b)} ; b \leq x \leq c
\end{array}\right.
$$

Bilangan TFN memiliki ketentuan skala seperti dapat dilihat pada Tabel 1. 
Tabel 1. Skala AHP dan Bilangan Triangular Fuzzy

\begin{tabular}{cccc}
\hline $\begin{array}{c}\text { Skala } \\
\text { AHP }\end{array}$ & Skala Fuzzy & Invers Skala Fuzzy & Definisi \\
\hline 1 & $(1,1,1)$ & $(1,1,1)$ & Sama pentingnya \\
2 & $(1,2,3)$ & $(1 / 3,1 / 2,1)$ & Nilai tengah \\
3 & $(2,3,4)$ & $(1 / 4,1 / 3,1 / 2)$ & Agak lebih penting yang satu atas yang lainnya \\
4 & $(3,4,5)$ & $(1 / 5,1 / 4,1 / 3)$ & Nilai tengah \\
5 & $(4,5,6)$ & $(1 / 6,1 / 5,1 / 4)$ & Cukup penting \\
6 & $(5,6,7)$ & $(1 / 7,1 / 6,1 / 5)$ & Nilai tengah \\
7 & $(6,7,8)$ & $(1 / 8,1 / 7,1 / 6)$ & Sangat penting \\
8 & $(7,8,9)$ & $(1 / 9,1 / 8,1 / 7)$ & Nilai tengah \\
9 & $(9,9,9)$ & $(1 / 9,1 / 9,1 / 9)$ & Mutlak penting \\
\hline
\end{tabular}

e. Menentukan nilai fuzzy synthetic extent untuk setiap kriteria dalam hierarki.

$$
\begin{aligned}
& S i=\sum_{j=1}^{m} M_{g i}^{j} x\left[\sum_{i=1}^{n} \sum_{j=1}^{m} M_{g i}^{j}\right]^{-1} \\
& \sum_{j=1}^{m} M_{g i}^{j}=\left(\sum_{j=1}^{m} l_{j}, \sum_{j=1}^{m} m_{j} \cdot \sum_{j=1}^{m} \mu_{j}\right) i=1,2, \ldots, n \\
& {\left[\sum_{i=1}^{n} \sum_{j=1}^{m} M_{g i}^{j}\right]=\left[\sum_{i=1}^{n} \sum_{j=1}^{m} l_{i j}, \sum_{i=1}^{n} \sum_{j=1}^{m} m_{i j}, \sum_{i=1}^{n} \sum_{j=1}^{m} \mu_{i j}\right] j=1,2, \ldots, m} \\
& {\left[\sum_{i=1}^{n} \sum_{j=1}^{m} M_{g i}^{j}\right]^{-1}=\left(\frac{1}{\sum_{i=1}^{n} \mu_{i}}, \frac{1}{\sum_{i=1}^{n} m_{i}}, \frac{1}{\sum_{i=1}^{n} l_{i}}\right)}
\end{aligned}
$$

Dengan $M$ adalah bilangan triangular fuzzy number, $m$ adalah jumlah kriteria, $i$ adalah baris, $j$ adalah kolom, dan $g$ adalah paramater $(l, m, \mu)$.

f. Membandingkan tingkat kemungkinan antar nilai fuzzy synthetic extent dengan nilai minimumnya.

Untuk dua bilangan triangular fuzzy $\mathrm{M}_{1}=\left(\mathrm{l}_{1}, \mathrm{~m}_{1}, \mu_{1}\right)$ dan $\mathrm{M}_{2}=\left(\mathrm{l}_{2}, \mathrm{~m}_{2}, \mu_{2}\right)$ dengan tingkat kemungkinan $\mathrm{M}_{2} \geq \mathrm{M}_{1}$ dapat didefinisikan sebagai berikut:

$$
\begin{aligned}
& V\left(M_{2} \geq M_{1}\right)=\sup \left[\min \left(\mu_{M 1}(x), \mu_{M 1}(y)\right)\right] \\
& V\left(M_{2} \geq M_{1}\right)=\left\{\begin{array}{cc}
1, & \text { jika } m 2 \geq m 1, \\
0 & \text { jika } l \geq \mu 2 \\
\frac{l_{1}-\mu_{2}}{\left(m_{2}-\mu_{2}\right)-\left(m_{1}-l_{1}\right)} & \text { untuk kondisi lain }
\end{array}\right.
\end{aligned}
$$

Untuk bilangan fuzzy konveks $M$ lebih baik dibandingkan sejumlah $k$ bilangan fuzzy konveks $M_{i}(i=1,2, \ldots, k)$ dapat ditentukan dengan menggunakan operasi max dan min sebagai berikut:

$$
\begin{gathered}
V\left(M \geq M_{1}, M_{2}, \ldots M_{k}\right)=V\left(M \geq M_{1}\right) \operatorname{dan}\left(M \geq M_{2}\right), \ldots,\left(M \geq M_{k}\right)=\min V\left(M \geq M_{1}\right), i \\
=1,2, \ldots, k
\end{gathered}
$$

g. Menentukan vektor bobot.

Jika diasumsikan bahwa $d^{\prime}\left(A_{i}\right)=\min V\left(S_{i} \geq S_{k}\right)$ untuk $k=1,2, \ldots, n ; k \neq i$ maka vektor bobot didefinisikan:

$$
W^{\prime}=\left(d^{\prime}\left(A_{1}\right), d^{\prime}\left(A_{2}\right), \ldots, d^{\prime}\left(A_{n}\right)\right)^{T}
$$


Dengan $A_{i}(i=1,2, \ldots, n)$ adalah $\mathrm{n}$ elemen dan $d^{\prime}\left(A_{i}\right)$ nilai yang menggambarkan pilihan relatif masing-masing atribut keputusan.

h. Me-normalisasi vektor bobot.

$$
\begin{aligned}
& W=\left(d\left(A_{1}\right), d\left(A_{2}\right), \ldots, d\left(A_{n}\right)\right)^{T} \\
& d\left(A_{n}\right)=\frac{d^{\prime}\left(A_{n}\right)}{\sum_{i=1}^{n} d^{\prime}\left(A_{n}\right)}
\end{aligned}
$$

\section{HASIL DAN PEMBAHASAN}

Kriteria Utama dan Sub Kriteria penilaian kerusakan beton pada bangunan gedung yang diidentifikasi berdasarkan studi literatur adalah sebagai berikut:

a. Kriteria Utama: Kondisi sejarah bangunan, terdiri dari sub kriteria:

a.1. Perubahan desain dan fungsi bangunan

a.2. Perubahan struktural

a.3. Riwayat kecelakaan

b. Kriteria Utama: Keadaan lingkungan, terdiri dari sub kriteria:

b.1. Paparan kandungan kimiawi

b.2. Paparan abrasi/erosi

b.3. Getaran tinggi

c. Kriteria Utama: Kapasitas struktural, terdiri dari sub kriteria:

c.1. Keretakan, terdiri dari sub sub kriteria:

c.1.1. Ukuran retak

c.1.2. Tipe retak

c.1.3. Riwayat retak

c.2. Defleksi dan deformasi, terdiri dari sub sub kriteria:

c.2.1. Balok

c.2.2. Pelat

c.2.3. Kolom

c.2.4. Dinding Geser

c.2.5. Dinding

c.3. Kemiringan dan penurunan

c.3.1. Kemiringan struktur

c.3.2. Penurunan tanah

d. Kriteria Utama: Durabilitas, terdiri dari sub kriteria:

d.1. Kerusakan permukaan, terdiri dari sub sub kriteria:

d.1.1. Lumut

d.1.2. Retak

d.1.3. Kebocoran

d.1.4. Kontaminasi

d.1.5. Pengelupasan

d.2. Kondisi tulangan, terdiri dari sub sub kriteria:

d.2.1. Paparan dan korosi pada tulangan 


\section{d.2.2. Lingkungan korosif}

d.3. Kondisi kerusakan finishing, terdiri dari sub sub kriteria:

\section{d.3.1. Interior}

\section{d.3.2. Eksterior}

Berdasarkan hasil pengolahan data dan analisis dari setiap tingkatan kriteria penilaian kerusakan beton pada bangunan gedung dapat ditetapkan skala prioritas seperti dilihat pada Gambar 1 .

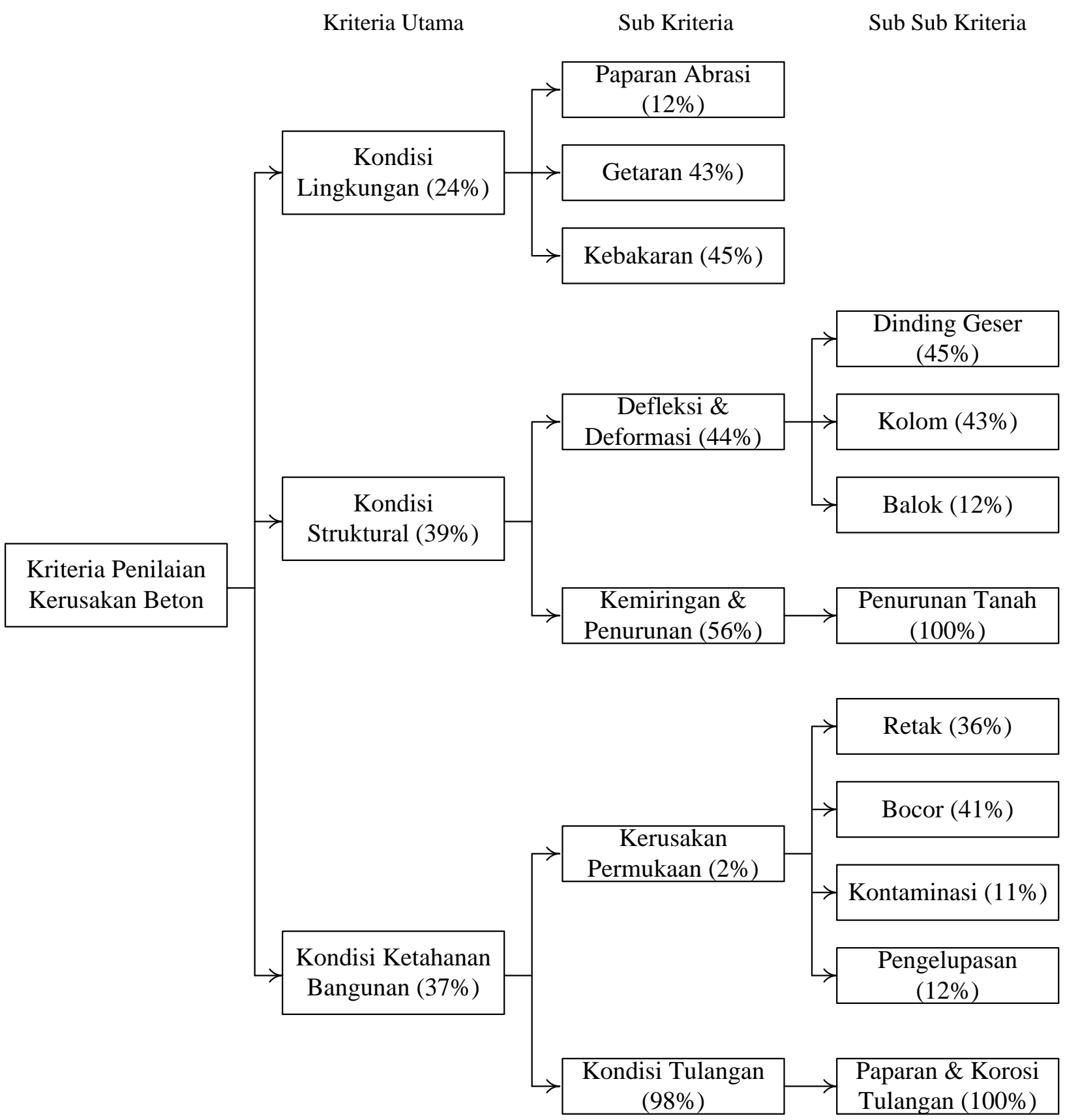

Gambar 1. Skala prioritas kriteria penilaian kerusakan beton 
Dari Gambar 1 dapat dilihat kriteria utama dengan prioritas tertinggi adalah kapasitas struktural yang diikuti oleh durabilitas, dan keadaan lingkungan. Untuk sub kriteria 1, dapat diketahui sub kriteria dengan prioritas tertinggi pada masing-masing kriteria adalah kondisi tulangan pada kriteria durabilitas, kemiringan dan penurunan pada kriteria kapasitas struktural, serta kebakaran pada kriteria keadaan lingkungan. Sedangkan untuk sub kriteria 2, dapat diketahui bahwa sub kriteria 2 dengan prioritas tertinggi pada masing-masing sub kriteria 1 adalah paparan dan korosi pada tulangan pada kondisi tulangan, penurunan tanah pada kemiringan dan penurunan, serta dinding geser pada defleksi dan deformasi.

\section{KESIMPULAN}

Hasil analisis menunjukan bahwa kriteria utama penilaian kerusakan beton pada bangunan gedung dengan prioritas tertinggi adalah kapasitas struktural. Prioritas tertinggi pada sub kriteria 1 adalah kondisi tulangan, dan prioritas tertinggi pada sub kriteria 2 adalah paparan korosi pada tulangan dan penurunan tanah. Secara keseluruhan kriteria penilaian kerusakan beton dengan skala prioritas tertinggi adalah paparan dan korosi pada tulangan, penurunan tanah, dan dinding geser. Berdasarkan hasil penelitian dapat diartikan pula bahwa kriteria dengan prioritas tertinggi merupakan aspek yang harus diperhatikan dalam perencanaan, pelaksanaan, dan pemeliharaan bangunan.

\section{REFERENSI}

American Society of Civil Engineers (ASCE). (2014). Guideline for Condition Assessment of The Building Envelope. ASCE/SEI 30-14.

Hamdia, KM, Arafa, M., Alqedra, M. (2018). Structural damage assessment criteria for reinforced concrete buildings by using a fuzzy analytic hierarchy process. Underground Space, 3(3), 243-249, September, Tongji University and Tongji University Press.

Kim, Yeong M., Kim, C. K., dan Hong, S. G. (2006). Fuzzy based state assessment for reinforced concrete building structures. Engineering Structures, vol. 28, no. 9.

Portland Cement Association (PCA). (2002). Types and Causes of Concrete Deterioration. Concrete Information IS536.

Saaty, Thomas L., dan Vargas, Luis G. (2001). Models, Methods, Concepts dan Application of The Analytic Hierarchy Process. International Series in Operations Research dan Management Science, vol. 34, no. 48, Springer Science+Business Media, LLC.

Zadeh, Lotfi A. (1999). Fuzzy Sets a Basis for a Theory of Possibilty. Fuzzy Sets and Systems, vol. 100, Elsevier B.V.

Undang-Undang Republik Indonesia. (2002). "Bangunan gedung." UU Nomor 28 Tahun 2002, Jakarta. 
PENETAPAN KRITERIA PENILAIAN KERUSAKAN BETON

Henny Wiyanto, et.al

PADA BANGUNAN GEDUNG BERDASARKAN SKALA

PRIORITAS 